\title{
Near-Death Experiences, Shamanism, and the Scientific Method
}

\author{
J. Timothy Green, Ph.D. \\ Capistrano Beach, CA
}

\begin{abstract}
The first 20 years of near-death studies have thoroughly documented the existence of this phenomenon. The field of near-death studies appears to be evolving from a purely academic one to include an applied, clinical component. I discuss the overlap between shamanism and near-death experiences (NDEs) and suggest that the study of shamanism would be helpful in more fully understanding this phenomena and beginning the development of an applied methodology. Although it may be difficult to verify subjective accounts of NDEs and shamanic journeys, from a clinical standpoint it may not be necessary to do so in order to develop a technique that passes the test of scientific scrutiny.
\end{abstract}

Near-death experiences (NDEs) may be able to claim status as the most thoroughly researched spiritual, mystical, transpersonal experience ever studied by modern Western scientists. Along with numerous articles in different scientific journals, the field of near-death studies has produced its own journal, now in its $16^{\text {th }}$ volume, a number of books of personal accounts (Brinkley and Perry, 1994; Eadie and Taylor, 1993; Harris and Bascom, 1990; Ritchie, 1991; Ritchie and Sherrill, 1978), anecdotal accounts (Atwater, 1988, 1994; Moody, 1975, 1977; Moody and Perry, 1988; Morse and Perry, 1990, 1992; Sharp, 1995; Sutherland, 1992, 1993), controlled studies (Grey, 1985; Ring 1980, 1984, 1992; Sabom 1982), surveys (Gallup and Proctor, 1982); theoretical discussions (Grosso, 1985; Lorimer, 1990); edited volumes (Greyson and Flynn 1984; Lundahl 1982) and historical reviews of similar experiences (Couliano, 1991; Platthy, 1992; Zaleski,

J. Timothy Green, Ph.D., is a clinical psychologist in private practice in Laguna Hills, CA. Reprint requests should be addressed to Dr. Green at P.O. Box 2788, Capistrano Beach, CA 92624. 
1987). More than 20 years after Raymond Moody (1975) first coined the term "near-death experience," researchers have now documented tens of thousands of these episodes, analyzed their components, and catalogued their aftereffects. All this led Moody to write recently that he was now aware that "the near death experience is an established fact in our culture" (in Weiss, 1992, pp. 13-14). He went on to write:

More and more, ordinary people are becoming comfortable talking about their visions and in exchanging information about various techniques for inducing or facilitating them.... I am fairly confident that within the next few years this research will proceed to the point at which profound experiences that can at least be called "psychic" and which may well be called "spiritual" can be readily facilitated in psychologically normal individuals. (Weiss, 1992, p. 13, italics added)

Although the first 20 years of near-death studies have been largely academic, if Moody is correct, a shift is now occurring to include an applied, clinical approach, at least in some quarters. Moody's own research into facilitated visionary encounters (Moody, 1993; Moody and Perry, 1993) represents the first applied methodology to emerge from the field of near-death studies. Moody (1995) has also recently spoken about what he refers to as "empathic near-death experiences," experiences often reported by a relative of someone who is dying, during which the person actually enters, to some degree, into the experience with the dying individual. In a recent paper, I (Green, 1995) suggested that the development of lucid dreaming may be another technique of replicating components similar to those known to occur during NDEs. Michael Grosso (1995) has recently said that he now advocates what he refers to as "taking the shamanic turn": "We have to go there, . . . in other words, to begin to explore the other world now." Moreover, he said that this process has already begun and cited Stanislav Grof's and Moody's work as evidence of this.

NDEs have been linked with a number of ancient traditions (Becker, 1984; Couliano, 1991; Greyson, 1993; Grosso, 1985; Moody, 1993; Moody and Perry, 1993; Platthy, 1993; Ring 1984; Rinpoche, 1992; Zaleski, 1987), many of which were not only religious or philosophical systems, but actual methods of direct spiritual experience. For instance, Grosso (1985) has argued that the ancient Greek and Egyptian initiation rituals were actually highly developed methods of inducing NDEs in young priests-in-training. John White (1995) has discussed the belief that the original form of baptism, full body immersion, was one in which the initiate was held under water until 
near drowning, thereby inducing a near-death experience. However, nowhere is the connection between NDEs and ancient traditions clearer than in the oldest of all spiritual traditions, shamanism. The purpose of this paper is to examine more closely the connection between shamanic experiences and NDEs, to suggest that NDErs would both benefit from, and be excellent candidates for, further training in shamanism, and to argue that by incorporating shamanism, the field of near-death studies could develop an applied methodology that would pass scientific scrutiny.

\section{The Overlap Between NDEs and Shamanism}

While shamanic practitioners have been quick to recognize and discuss the phenomenological overlap between NDEs and shamanism (Halifax, 1990; Harner, 1980; Harner and Doore, 1987; Ingerman, 1991; Kalweit, 1984, 1987; Peters, 1990; Walsh, 1990), researchers and writers in the area of near-death studies appear to have been less aware, or at least have written less about, this connection. The one exception is Kenneth Ring $(1990,1989)$ who has written about the overlap between NDEs and the shamanic journey. Ring wrote:

By coming close to death, the NDEer has inadvertently and involuntarily been initiated into a shamanic journey. According to this view, then, the NDEers are modern shamans, and the NDE itself may be understood to be a classic form of shamanic initiation. In summary, the NDE is, in its form and dynamics, essentially a shamanic experience-whether the NDEer realizes it or not. (1990, p. 208)

Ring has also commented on the connection between the realm entered by NDErs and shamans, as well as the accessibility of that realm:

By taking this shamanistic perspective, we can appreciate that the plane of experience NDEers enter into during their near-death crisis is the same one that shamans learn to access freely during the course of their training. Therefore, strictly speaking, this realm is not one that awaits us only after death. It exists now and is in principle available in life to anyone who has learned the access code." (1990, p. 209)

Too often in the past, the NDEr not only failed to realize that he or she has had a shamanic experience, but may have never heard of shamanism. Regardless, shamans would agree with Ring that an 
NDE is a classic form of shamanic initiation (Halifax, 1990; Ingerman, 1991; Peters, 1990). Although shamanic initiations take many different forms, and not all are associated with a close brush with death, the literature is replete with examples of shamans who began their vocation following an NDE.

However, students and practitioners of shamanism would be quick to point out that having an NDE does not, by itself, grant someone the status of being a shaman, a point Ring acknowledged in a footnote. While the NDEr has entered the same realm as the shaman, he or she did so only once, and does not always have the ability to repeat the experience. In contrast, the shaman has become, in Mircea Eliade's words, a "master of ecstasy" (1964, p. 4), one who is adept at consciously moving between the planes of existence at will and for a specific purpose. Following the shaman's initial contact with this realm, he or she becomes an apprentice to a master shaman. In shamanic cultures, the young initiate is then slowly taught all of the techniques that comprise the art of shamanism. Only then does the individual begin to practice his or her craft within the community. The final status of shaman is conferred upon them by members of their community based on their performance.

Although there are a number of different types of shamanic practitioners, an individual is generally not considered a shaman unless he or she engages in shamanic journeys, during which the shaman leaves the physical body and enters into the shamanic realm. Anthropologist and practicing shaman Michael Harner commented on the similarity between the shamanic journey and NDEs:

The shaman's journey starts with an experience of going through a tunnel of some kind, usually with a light at the end, and this is very similar to descriptions of the so-called near-death experiences. But the shaman goes all the way through the tunnel and explores the world into which it opens at the end, the world that people feel themselves passing into at the time of death. (Harner and Doore, 1987, pp. 5-6)

A person who has had an NDE, until recently, has had nowhere to turn in order to understand and begin to integrate his or her experience. Prior to Moody and Elisabeth Kübler-Ross's work these experiences were largely dismissed or, worse, pathologized. Despite the intense interest in NDEs throughout the past two decades, there continues to be no formal method of integrating and understanding these experiences. 
I believe that by studying shamanism, and incorporating it into our knowledge of NDEs, we will add important insights into our understanding of this phenomenon. First, individuals who have had deep NDEs may be able to integrate their experience more quickly by studying and practicing shamanic techniques. Many NDErs report problems following their experience, not the least of which is an intense desire to return to the state they found themselves in during their NDE. By learning the art of shamanic journeying, they are actually able to enter this state consciously, repeatedly, and at will. For example, Sandra Ingerman has told me in a personal communication that during her NDE she found herself in a garden-like area of preternatural beauty, which is often described by NDErs. She reported that she can return to that garden at will during a shamanic journey by simply holding an intention to do so; however, she stated that the wonderful sense of peace and calmness that was one aspect of her NDE is not present during her shamanic journeys. Many NDErs also return from their experience with an intense desire to help others. By developing the skill of shamanic journeying, NDErs could become shamanic healers. It behooves us, then, as students of NDEs, to take a closer look at the ancient art of shamanism.

\section{Shamanism}

Shamanism is an ancient tradition of healing believed to be at least 20,000 to 30,000 years old (Eliade, 1964; Harner, 1980; Walsh, 1990). Although almost completely suppressed in most Western cultures, shamanism has been continuously practiced, in one form or another, in many tribal and preliterate cultures throughout the world. Despite differences in other aspects of culture, as well as vast geographical and time differences, many of the basic practices, techniques, and beliefs that comprise shamanism are amazingly similar crossculturally (Harner, 1980; Walsh, 1990). This similarity led Roger Walsh to suggest that spontaneous NDEs, out-of-body experiences, and lucid dreams may have been the inspiration for consciously induced shamanic journeys:

Yet around the world people who have never even heard of shamanism may be surprised to find themselves having journeylike experiences. These may erupt spontaneously and entirely unsought as out-of-body experiences (OOBEs), lucid dreams, or near-death experiences (NDEs). Such experiences have presumably occurred through- 
out human history. As such they may have provided the inspiration for consciously induced journeys, first in shamanism, then in other religious traditions, and most recently in psychotherapy. (1990, p. 148)

The master shaman is a medicine man, a soul doctor, who has acquired a great deal of information about ancient techniques of healing a variety of physical, psychological, and spiritual problems. Through their long apprenticeship, shamans master a number of ancient arts of healing, which they use in maintaining the well-being and health of members of their community. And although there are a number of different techniques, central to all shamanic activity is the "shamanic journey."

\section{The Shamanic Journey}

During a shamanic journey, the shaman enters into an altered state of consciousness, referred to by Harner $(1980$, p. xvi) as the Shamanic State of Consciousness (SSC), and wills himself or herself to have an out-of-body experience (OBE). There are a number of different methods of achieving this state, but the one most frequently used is prolonged drumming. Once having achieved the OBE, the shaman enters into a nonordinary reality and travels to one of the three realms for a specific purpose.

Shamanic cosmology postulates three different, but interpenetrating realms of existence: the Middle World, which corresponds roughly to physical reality; the Upper World; and the Lower World. These realms are believed to be a real, although nonordinary reality, rather than simply mental constructions or metaphors for psychological states. The shaman enters into an altered state of conscious, thus using his mind to "gain access, to pass through a door into another reality that exists independently of that mind" (Harner and Doore, 1987, p. 4). Shamans believe that these worlds are populated by spirits that are accessible to people at death or in an altered state of consciousness. The shaman actively enters into the world of spirits and interacts with them, enlisting their aid and instruction in how to help care for the lives of the people to whom they minister. The shaman is said to control the spirits, at least in the sense that he or she has an ongoing relationship in which these spirits help and participate. 
Through repeated journeys, the shaman becomes familiar with both the geography and the inhabitants of these different realms. While doing so, he or she enlists the aid of helping spirits, often in the form of animals, who assist the shaman in learning the various methods of curing illnesses, disorders, or diseases. These helping spirits are called power animals. The shaman will also acquire a spirit teacher, often referred to as a tutelary spirit, who acts as a teacher during his or her journeys. From the shamanic perspective all things are thought to be endowed with spirit; animals, plants, even minerals possess a spiritual essence, and it is the shaman who has the ability to communicate directly with these spiritual entities.

\section{Shamanic View of Ilness}

In the shaman's view, many illnesses are the result of being literally dis-spirited; either the person's spirit has left the body and not returned, or the individual has lost the aid of one of his or her helping spirits. In either case, the shaman will undertake a shamanic journey in order to attempt to find and bring back the missing spirit. If the shaman is successful, the patient should then be relieved of symptoms and restored to health.

The shaman is also a psychopomp, a conductor of souls between this world and the world of the dead. Shamans believe that people who have recently died, especially under sudden circumstances, are often confused and disoriented. The shaman enters a trance state, travels into nonordinary reality, finds the wandering soul, and assists in directing it to where it can find help.

The shaman is also a seer (see-er), one who engages in divination to see into the future in order to help those in his or her community. This is often done with the help of a quartz crystal. The shaman will stare into the quartz while focusing his or her intention on a particular question and will "see" the answer within the rock. Dreams also play a major part in shamanic activities. The shaman believes that there are two different types of dreams: ordinary dreams and nonordinary dreams, which are also known as "big dreams." A "big dream" is described as a "dream that is so vivid that it is like being awake, an unusually powerful dream" (Harner, 1980, p. 127).

Shamanism is, then, basically an applied therapeutic methodology. It is, however, a methodology based on a different, expanded view of 
reality and dependent upon the practitioner's ability to enter into an altered state of consciousness and successfully execute a particular task. And one thing is clear: people who have had deep NDEs are excellent candidates for further training in shamanism. While many people who seek out training in shamanism undergo difficult, even dangerous initiations, in the case of NDErs, the worst has already happened! NDErs have died, been to the other side, and returned. And they often return expressing a deep desire to enter into the helping professions. What better way to express this than by building on their experience and training to become a shaman, training that now is available in the Western world.

\section{The Work of Michael Harner}

Harner is an anthropologist by training who, since the death of Eliade, has been widely recognized as the leading authority in the world on shamanism. Harner is more than an armchair authority on the subject, having himself been initiated into shamanism while conducting field work among the Conibo Indians in the upper Amazon. He is also a practicing shaman and teacher of shamanism. It is interesting to note how Harner himself was initiated into the world of shamanism. While living among the Conibo, Harner's ethnographic fieldwork was proceeding well. However, he found the Conibo reluctant to discuss their religious beliefs. After repeatedly questioning them about their spiritual views, he was told that in order to learn about their religion he would have to experience it first hand by taking ayahuasca, a powerful psychedelic drug used in their religious ceremonies.

Harner agreed to undergo the initiation and the ceremony began late in the afternoon. As the drug began to take affect, Harner had a number of visions, one of which was of a large vessel with a dragonhead prow filled with figures resembled ancient Egyptian depictions of birdmen. Harner wrote that at that moment, "Although I believed myself to be an atheist, I was completely certain that I was dying and that the bird-headed people had come to take my soul away on the boat" $(1990$, p. 4). Later in the experience he felt close to death:

Now I was virtually certain I was about to die. As I tried to accept my fate, an even lower portion of my brain began to transmit more visions and information. I was "told" that this new material was being presented to me because I was dying and therefore "safe" to 
receive these revelations. These were secrets reserved for the dying and the dead, I was informed. (1980, p. 5; italics added)

Again we find the overlap between the shamanic experience and the theme of death. Harner's experience was more of an ego death, rather than a physical death, and was similar to the experiences reported by Grof and Joan Halifax (1977) in their early work in psychedelic psychotherapy. Since his first initiation, Harner has worked in other shamanic traditions and discovered that, although powerful psychedelic drugs are used in some cultures, many people can easily learn to journey without these substances. In fact, sustained drumming, rattling, singing, and dancing are used in most shamanic cultures to gain access to the shamanic realm.

Harner has been very instrumental in making shamanic techniques widely available to Westerners. Many people who have had NDEs do attend his workshops, and Harner has commented on the connection between newly initiated shamans and NDErs:

The new shamans often cry tears of ecstasy when undergoing and recounting their experiences. They talk with mutual understanding with persons who have had near-death experiences and see hope where others may see hopelessness. (1980, xiv)

Through his workshops he has exposed thousands of Westerners to these ancient techniques. He reports that over 90 percent of his students have some success with shamanic techniques after even brief exposure. Many people report their journey experiences are very real in nature and easily distinguishable from fantasy or imagination. And although some people have more innate talent, Harner maintains that anyone can learn to enter into the shamanic realm with practice. Harner teaches what he refers to as core shamanism, which is his own distillation of the basic techniques practiced by shamans throughout the world. He differentiates between what he refers to as the Ordinary State of Consciousness (OSC) and the Shamanic State of Consciousness (SCC). While the OSC is the consensual reality that most of us share, the shaman is also able to enter into the SSC, which puts him or her in touch with the shamanic realm.

\section{Soul Loss and Soul Retrieval}

Ingerman is one of Harner's closest colleagues, and an accomplished shaman in her own right; she is not only an shaman, but 
also an NDEr. She discussed her own NDE and how it impacted the development of her shamanic skills:

Many survivors of near-death experiences report going to a great blinding light that pulsates only love. In my own near-death experience in 1971, I too, was received by the light. For me, this light represented the Father and Mother God. I started thinking about God's being pure light. ... .

Traditionally shamans have been people who have had a neardeath experience, life threatening illness, or a psychotic break. In my case, I almost drowned, and this near-death experience showed me the way to the other side. (1991, pp. 202)

The author of Soul Retrieval (1991) and Welcome Home (1994), Ingerman discussed her work as a modern shaman helping those who suffer from soul loss. Modern soul loss is often the result of traumatic events such as incest, abuse, loss of a loved one, surgery, accident, illness, miscarriage, abortion, the stress of combat, addiction, verbal abuse, or divorce. Although the accepted treatment for most of these disorders is psychotherapy, Ingerman pointed out that from the shamanic perspective, psychotherapy cannot be effective if the aspect of personality we are addressing is not present.

In retrieving a soul, the shaman's task is to enter into nonordinary reality and first locate the soul. Once the soul has been located, the shaman must then convince it to return to ordinary reality and reintegrate with the individual. Ingerman discussed the case of a man named David who came to her for a shamanic healing. He was in very poor physical condition at the time with Epstein-Barr virus as well as a number of other infections. He mentioned that just prior to his becoming sick, his girlfriend, whose name was Suzanne, had committed suicide. This alerted Ingerman to the possibility that this might have been a case of not just soul loss, but soul stealing. The following is also an excellent example of psychopompic work, during which the shaman helps the deceased soul become better situated in the afterlife. As Ingerman entered into the shamanic trance using sustained drumming:

I repeat my intention to focus myself. As I walk, I come to a tree where I see David tied by a rope around the trunk. He looks very forlorn and spiritually beaten. His head hangs down, and his soul shows no vitality. I don't like what I see, and I feel sensations of deep anger in my solar plexus. I yell out in nonordinary reality for my power animal to come and help me. No sooner do I call than he appears. He is just in time! Suddenly a woman jumps out from behind the tree where she is hiding and lunges at me with her im- 
posing nails aimed at my face. My power animal steps in front of me, creating a force field around us that she can't break through. She repeatedly lunges at the field in anger but keeps being thrown backward into the leaves. Finally, when she is exhausted, we carefully let the field down and walk close to her. She bursts into tears and begins sobbing. She is Suzanne. (Ingerman, 1991, p. 105)

Ingerman asked the woman whether she knows that she is dead, and she answered yes. Ingerman told Suzanne that she could help her move to a more comfortable place, but in order to do so, she would have to release David's soul. She refused. Ingerman then turned to her power animal for help and was told to keep the conversation going:

"David is dying back in ordinary reality, because you are keeping his soul captive." "That's good," she replies. "I want him to die, so he can keep me company here. I want him to stay with me forever." (1991, p. 105)

Although shamans are able to intervene, they are not able to hurt or impose their will on others. Ingerman was now in the position of having to convince the woman to release the soul:

I reach into my pocket and pull out a quartz crystal and hand it to her. She loves the sparkling light, which starts to whirl around and through her. She obviously is soaking it up.

"I can take you to a place where the light shines all the time and will take care of you." She asks, "How do I get there?" "Give me back David's soul, and I'l take you there." Suzanne looks at the crystal and then at David and then at me. Seconds go by that seem like hours, and finally she agrees to release David. I untie David from the tree. He slides to the ground, lying still; his breathing is shallow. I leave him there in the care of my power animal. I put my arm around Suzanne's and we float upward. We continue to move up and out of this place and travel through space, surrounded by planets and stars. Suddenly we come to a skin membrane, which we break through. Our pace quickens as we continue to rise, going through layer upon layer of clouds. In the distance there is a blinding light. I know I can go no further. "Suzanne, go to the light." At this point I push her up, watching her disappear into the all-encompassing golden rays. (1991, pp. 105-6)

After returning with the soul parts, the shaman will then blow them back into the client's body and seal the parts in by rattling around the person. When Ingerman did so with David, he reported feeling an immediate rush, his eyes brightened, and his physical condition gradually improved. Ingerman reported that he continues to enjoy good health to this day. 


\section{Shamanic Extractions}

Often shamanic healings call for the extraction of some foreign object or element from the body. Larry Peters (1993) has written about an extraction he performed while in the small country of Tuva, where he was traveling as part of an expedition for Harner's Foundation for Shamanic Studies. One evening the expedition members, who were all shamanic practitioners, were invited to a gathering. When they arrived, they were quickly ushered on to a stage where a man with a serious heart condition had been brought. The man was so ill that he had come directly from his hospital bed to be seen by the visiting shamans. Peters described his experience as the group stood in a circle around the man:

[O]ur group began drumming quickly, each singing our own spirit song softly. After possibly ten to fifteen minutes of intense drumming, Gajandra [his teacher] appeared to me in a vision. He came out of the sky as a thunderbolt that struck my heart. I found it difficult to breathe. My body began to shake, first my belly, then the rest of my body. The rattle in my hand moved with nervous energy. I wanted to shout "Stop!" But I was overwhelmed and couldn't stop. My whole body was shaking. Gajandra had penetrated into my being, into my body. In the vision, I heard Gajandra say, "Get up, get up, get up."

Tears flowed from my eyes, as I saw in the vision a golden nugget emanating light, first in the sky above. Then I was standing outside myself, observing myself, and the golden light was now encircling my head, now in my heart, now surrounding my body. I heard bells ringing on my feet, and I saw myself dancing. I was witnessing a person who looked like me. Was that me dancing? I looked down on the circle of drummers, and I watched myself dancing for a long time, circling the patient and the drummers. $(1993$, p. 46)

This is an excellent description of the ecstatic nature of the shamanic experience. Ten to 15 minutes into the drumming and singing, Peters had left his body and was witnessing the scene from above. When he returned to his body, he found himself transformed:

I'm not exactly sure how I returned to my body, but I became aware I was kneeling next to the patient, clawing at black poisonous spiders and other insects I saw crawling in his veins. I saw large wasps with huge stingers in his heart. I growled and hissed as I jumped at the insects. I thought to myself, "I'm behaving like a tiger." Suddenly I was an orange, black, and white tiger with large saber fangs-the tiger Gajandra had taught me to be, the tiger that bites and sucks flesh at healing ceremonies. I bit and sucked out the insects. I felt their sharpness inside my mouth, then spit them out. 
There were so many I thought I'd never get them all. I sucked the man's back. I bit and sucked his sides and rolled his body over. Saliva covered my face as I growled and bared my teeth. Picking up his shirt, I went straight for his heart.

At the time, I didn't know how long I had worked on the man. As I shape-shifted back into ordinary reality and fell back into my seat in the circle of drummers, I was exhausted. Sweat was pouring from me. I felt dazed and unbalanced. I remember feeling out of time, and I kept holding onto my colleagues for reassurance. The patient was visibly shaken. His hands and body continued to tremor as he was hurriedly escorted back to the hospital ambulance that brought him. (1993, pp. 46-47)

Although Peters was deeply concerned, he later learned that the man's condition had improved dramatically. In fact, when he visited with the man and his family a week later:

[H]e was vibrant, smiling and joking and embracing his wife. As his family served us dinner, he said he felt no pain. He sat tall. It was as if he were another person. He talked about going back to work. He had developed a passion for life, disclosing that he had changed his diet, and I noticed that he didn't drink while the others toasted each of us. His coloring and countenance had completely changed. (1993, p. 47)

\section{Active Dreaming}

Another dramatic healing comes from the work of Robert Moss (1994). Moss, who incorporates both shamanic techniques and dream work in his approach, which he refers to as active dreaming, described the experience of a woman named Wanda, a natural healer who had worked with Moss for several years. Over a period of 20 years Wanda had a recurring dream during which she was told that she would die in her $40 \mathrm{~s}$. She was diagnosed with breast cancer at age 43. The cancer was felt to be spreading quickly and she underwent a modified radical mastectomy and chemotherapy. During and following the chemotherapy, she was having a very difficult time. Moss journeyed on her behalf:

One night in a hypnogogic dream state, I journeyed to check on her. I found her in a night setting, near a cave that was also a temple. A circle of women were performing a ritual nearby, but Wanda was not part of it. She was frozen, paralyzed in terror of some shadowy, snakelike forms that menaced her on all sides. I grabbed two of the "snakes" and wound them into the form of a caduceus. Instantly, 
the healing staff came brilliantly alight in my hand. It radiated intense golden light. I touched Wanda with it. She promptly vanished. (Moss, 1994, p. 22)

Wanda later told Moss that she had also had a dream that night, a dream in which he had "flooded her with light." Following the dream she also felt buoyant and released from the malaise of the past weeks. Apparently, this dream energized Wanda and prepared her for a dream that she had on the night before her $44^{\text {th }}$ birthday, a dream that Moss wrote "quite literally, gave her a new lease on life" (1994, p. 22). Wanda dreamt:

I am climbing to the top of a mountain where an awesome presence is waiting for me. I know that this powerful being sent the messenger who told me I had to leave Earth. It moves like waves of light. It conveys its wishes and emotions by thought. I am terrified, but I never back away. The entity reminds me that I agreed before I came to this planet that I would leave at forty-three. I acknowledge this is true. I am shown a contract with my signature on it.

I argue that this contract should not be executed. I tell the entity that I didn't want to come here when I made the contract. But now I have people that I love and people I believe I can help to heal, because of my own experiences. I tell him, "You must know this, because you allowed me to discover my illness through dreams before my time was spent."

There is a time lapse. It seems like an eternity. Then I am presented with a new contract. I am given more time to help others. (Moss, 1994, p. 22)

Awakening from this dream, Wanda found herself trembling and crying with joy. Later, she told Moss that the dream was unlike any she had ever had before because she was both awake and asleep at the same time, which is a description of a lucid dream.

\section{Shamanism and Applied Science}

Shamanism is a method that honors traditional biological and psychological interventions, rather than attempting to compete with them. The cases presented above are examples of dramatic cures that provide intriguing anecdotal evidence for the effectiveness of shamanic techniques. However, my own belief is that shamanism will need to pass the test of scientific scrutiny before it achieves wider acceptance in our society. Fortunately, this may be easier than it might appear. 
In the case of NDEs, it is difficult to verify that the experiences reported actually occurred. In other words, while remaining in the Ordinary State of Consciousness, it is impossible for a researcher to prove scientifically that someone has left the physical body, traveled down a tunnel, entered into a light, met and conversed with dead friends and relatives, and so on. The experience itself is subjective and, like all other subjective phenomena, is impervious to direct scientific study.

A similar situation exists in dealing with shamanic journeys. Unless the researcher is able to enter into the Shamanic State of Consciousness, and travel with the practitioner into these realms, it is impossible to verify that the shaman did, in fact, do so. However, from a purely clinical perspective, there is no need to verify the subjective aspect of shamanic interventions. In order to employ it ethically as a viable treatment modality, we need prove only that the treatment was effective in alleviating the problematic condition, that it is safe, and that it is other than placebo. The underlying theory about why these techniques are effective can remain theoretical indefinitely.

Similar situations occur quite often in modern medicine. To take just one example, no one has been able to identify which pharmacological action of some of the new generation of antidepressant medications is the active mechanism in alleviating depression. In other words, what happens once the person takes the medication, how it works within the brain to alleviate depressive symptoms is, in a sense, a subjective experience. At this point, all we can do is theorize about what may be happening inside the brain that results in symptom relief. Despite this, we are able to prove these medications are effective in treating depression using the most rigorous scientific methods, and because of this, we use them, assuming that further research will someday answer the question of why they work.

In the case of shamanic interventions, many Western practitioners have now begun to use the methods, some with great success. And they have also set forth a theory, the same theory that also underlies NDEs, that some individuals are able to enter into the shamanic or spiritual realm, journey to different geographical areas, interact with spiritual beings that exist in those areas, and bring back information that is helpful in alleviating human suffering. And although they cannot at this time prove their theory, the effects of their interventions are objective facts that are well within the realm of the most rigorous scientific study. Although these studies have yet to be done, if shamanic techniques can be shown to be effective, they should be em- 
ployed along with biological and psychological treatments. To refuse to do so, simply because one holds a worldview inconsistent with the theory underlying this particular treatment modality, should be considered unethical, the ethical consideration being the best interest of the patient.

Finally, although there is no longer any controversy around the issue of whether NDEs are reported, skeptics have always been able to dismiss these accounts because they are subjective phenomena. However, every successful shamanic intervention also provides evidence in support of the theory underlying NDEs. As shamanism gains wider acceptance, what was theory will slowly become accepted scientific fact, at which point the shift in paradigms will have been completed.

\section{Conclusion}

A profound shift in paradigm is already well underway, and the field of near-death studies can pride itself for having played a major role in this shift. After 20 years of research into near-death experiences, investigators have thoroughly documented the existence of this phenomenon. An entire generation has grown up hearing and reading about these accounts, which are now taken for granted. We are now in a position enter into a new phase, evolving from pure science, to the development of a therapeutic modality, one based on spiritual principles, that will stand side by side with biological and psychological treatments. If we recognize the overlap between NDEs and shamanism, and realize that much of the work has already been done by shamans who have kept these sacred techniques alive, we will have an excellent starting point. This knowledge has been brought back to Western culture and is now available to anyone who chooses to walk the path of the shaman. NDErs have, in fact, already begun to tread this path and, for those who choose to pursue it, formalized training in shamanism may help them realize the true potential of their experience.

\section{References}

Atwater, P. M. H. (1988). Coming back to life. New York, NY: Dodd, Mead. 
Atwater, P. M. H. (1994). Beyond the light: What isn't being said about the near-death experience. New York, NY: Birch Lane Press.

Becker, C. B. (1984). The Pure Land revisited: Sino-Japanese meditations and neardeath experiences of the next world. Arabiosis: The Journal of Near-Death Studies, 4, 51-68.

Brinkley, D., and Perry, P. (1994). Saved by the light. New York, NY: Villard Books.

Couliano, I. P. (1991). Out of this world: Otherworldly journeys from Gilamesh to Albert Einstein. Boston, MA: Shambhala.

Doore, G. (Ed.). (1988). Shaman's path. Boston, MA: Shambhala.

Eadie, B., and Taylor, C. (1993). Embraced by the light. Placerville, CA: Gold Leaf Press.

Eliade, M. (1964). Shamanism: Archaic techniques of ecstasy. Princeton, NJ: Bollingen Foundation/Princeton University Press.

Gallup, G., and Proctor, W. (1982). Adventures in immorality: A look beyond the threshold of death. New York, NY: McGraw-Hill.

Green, J. T. (1995). Lucid dreams as one method of replicating components of a neardeath experience in a laboratory setting. Journal of Near-Death Studies, 14, 49-59.

Grey, M. (1985). Return from death. London, England: Arkana.

Greyson, B. (1993). Near-death experiences and the physio-kundalini syndrome. Journal of Religion and Health, 32, 277-290.

Greyson, B., and Flynn, C. F. (Eds.). (1984). The near-death experience: Problems, prospects, and perspectives. Springfield, IL: Charles C Thomas.

Grof, S., and Halifax, J. (1977). The human encounter with death. New York, NY: Dutton.

Grosso, M. (1985). The final choice: Playing the survival game. Walpole, NH: Stillpoint.

Grosso, M. (1995). Panel Discussion. The experience of dying: Psychological, spiritual and philosophical implications. Presented at the Spirit in Action Conference of the International Transpersonal Association.

Halifax, J. (1990). The shaman's initiation. ReVision, 13(2), 53-58.

Harner, M. (1980). The way of the shaman: A guide to power and healing. New York, NY: Harper and Row.

Harner, M., and Doore, G. (1987). The ancient wisdom in shamanic cultures. In S. Nicholson (Ed.), Shamanism: An alternate view of reality (pp. 3-16). Wheaton, IL: Theosophical Publishing House.

Harner, M. (1988). Shaman's path: Healing, personal growth, and empowerment (G. Doore, Ed.). Boston, MA: Shambhala.

Harris, B., and Bascom, L. (1990). Full circle: The near-death experience and beyond. New York, NY: Pocket Books.

Ingerman, S. (1991). Soul retrieval. San Francisco, CA: HarperCollins.

Ingerman, S. (1994). Welcome home. San Francisco, CA: HarperCollins.

Kalweit, H. (1984). Dreamtime and inner space. Boston, MA: Shambhala.

Kalweit, H. (1987). Shamans, healers and medicine men. Boston, MA: Shambhala.

Lorimer, D. (1990). Whole in one: The near-death experience and the ethic of interconnectedness. London, England: Arkana.

Lundahl, C. R. (Ed.). (1982). A collection of near-death research readings. Chicago, IL: Nelson-Hall.

Moody, R. A. (1975). Life after life. Covington, GA: Mockingbird Books.

Moody, R. A. (1977). Reflections on life after life. St. Simon's Island, GA: Mockingbird Books.

Moody, R. A. (1993). Family reunions: Visionary encounters with the departed in a modern-day psychomanteum. Journal of Near-Death Studies, 11, 83-131.

Moody, R. A. (1995). Panel discussion. The experience of dying: Psychological, spiritual, and philosophical implications. Presented at the Spirit in Action Conference of the International Transpersonal Association. 
Moody, R. A., and Perry, P. (1988). The light beyond. New York, NY: Bantam.

Moody, R. A., and Perry, P. (1993). Reunions: Visionary encounters with departed loved ones. New York, NY: Villard.

Morse, M., and Perry, P. (1990). Closer to the light: Learning from the near-death experiences of children. New York, NY: Villard.

Morse, M., and Perry, P. (1992). Transformed by the light: The powerful effect on people's lives of near-death experiences. New York, NY: Villard.

Moss, R. (1994). An active approach to death, dying, and healing dreams. Shaman's Drum: A Journal of Experiential Shamanism, No. 34.

Peters, L. (1990). Mystical experiences in Tamang shamanism. ReVision, 13(2), 71-85.

Peters, L. (1993). In the Land of Eagles: Experiences on the shamanic path in Tuva. Shaman's Drum: Journal of Experiential Shamanism, No. 33.

Platthy, J. (1992). Near-death experiences in antiquity. Santa Claus, IN: Federation of International Poetry Associations of UNESCO.

Ring, K. (1980). Life at death: A scientific investigation into the near-death experience. New York, NY: Coward, McCann, and Geohegan.

Ring, $\mathrm{K}$ (1984). Heading towards omega: In search of the meaning of the near-death experience. New York, NY: Morrow.

Ring, K (1989). Near-death and UFO encounters as shamanic initiations: Some conceptual and evolutionary implications. ReVision, 11(3), 14-22.

Ring, K (1990). Shamanic initiation, imaginal worlds, and light after death. In G. Doore (Ed.), What survives? Contemporary explorations of life after death (pp. 204215). Los Angeles, CA: Tarcher.

Ring, K (1992). The Omega Project: Near-death experiences, UFO encounters, and Mind at Large. New York, NY: Morrow.

Rinpoche, S. (1990). Tibetan book of living and dying. San Francisco, CA: HarperCollins.

Ritchie, G. (1991). My life after dying: Being alive in universal love. Norfolk, VA: Hampton Roads.

Ritchie, G., and Sherrill, E. (1978). Return from tomorrow. Waco, TX: Chosen Books.

Sabom, M. B. (1982). Recollections of death: A medical investigation. New York. NY: Harper and Row.

Sharp, K. (1995). After the light: What I discovered on the other side of life that can change your world. New York, NY: Morrow.

Sutherland, C. (1992). Transformed by the light: Life after near-death experiences. Sydney, Australia: Bantam.

Sutherland, C. (1993). Within the light. Sydney, Australia: Bantam.

Walsh, R. (1990). The spirit of shamanism. Los Angeles, CA: Tarcher.

Weiss, B. (1992). Through time into healing: Discovering the power of regression therapy to erase trauma and transform mind, body, and relationships. New York, NY: Simon and Schuster.

White, J. (Ed.) (1995). What is enlightenment? Exploring the goal of the spiritual path. New York, NY: Paragon House.

Zaleski, C. (1987). Otherworld journeys: Accounts of near-death experience in medieval and modern times. New York, NY: Oxford University Press. 